\title{
Synthesis and Pigmental Properties of Nickel Phosphates by the Substitution with Tetravalent Cerium Cation
}

\author{
Hiroaki Onoda, Takeshi Sakumura
}

Department of Informatics and Environmental Sciences, Faculty of Life and Environmental Sciences, Kyoto Prefectural University, Kyoto, Japan.

Email: onoda@kpu.ac.jp

Received August 15 $5^{\text {th }}, 2011$; revised September $27^{\text {th }}, 2011$; accepted October $12^{\text {th }}, 2011$.

\begin{abstract}
In this paper, we report the preparation of nickel phosphate in aqueous solution and its use as inorganic pigment. Because cerium phosphate is insoluble in acidic and basic solution, the addition of cerium was tried to improve the acid and base resistance of nickel phosphate pigment. The cerium substituted nickel phosphates were prepared from phosphoric acid, nickel nitrate, and ammonium cerium nitrate solution. The additional effects of tetravalent cerium cation were studied on the chemical composition, particle shape and size distribution, specific surface area, color, acid and base resistance of the precipitates and their thermal products.
\end{abstract}

Keywords: Inorganic Compounds, Chemical Synthesis, Precipitation, X-Ray Diffraction, Optical Properties

\section{Introduction}

Phosphates have been used for ceramic materials, catalysts, fluorescent materials, dielectric substances, metal surface treatment, detergent, food additives, fuel cells, pigments, etc. [1-3]. Especially, as a pigment, these materials have good anticorrosion properties for oxidation reaction and suitable for coating [4-7]. However, there is a weak point that is a certain degree of solubility for acidic and basic solution.

It is well known that rare earth phosphates are insoluble for acidic and basic solution in the groups of phosphate materials. In general, the addition of rare earth elements gives higher functional properties to the material [8]. Consequently, the addition of rare earth cation had the anticipation to improve the acid and base resistance of inorganic phosphate pigments and pigmental properties [9-11].

The substitution with lanthanum in nickel and cobalt phosphate materials was studied on the chemical composition, powder condition, color, acid and base resistance in previous works $[12,13]$. Specific surface area of phosphates increased and particle size became larger by the substitution with lanthanum. The substitution with lanthanum was effective on acid and base resistance for design of inorganic phosphate pigment. However, the color of phosphate materials was whitened by the sub- stitution with lanthanum.

Cerium cation is also one of rare earth cation. The different phenomena are expected with lanthanum cation, because cerium cation has stable tri- and tetra-valent states [14]. Generally, tetravalent cerium cation forms the yellow materials. Therefore, the substitution with tetravalent cerium cation is suitable to improve the acid and base resistance of yellow pigments. In this work, nickelcerium (+IV) phosp hates were synthesized in aqueous solution. The obtained products were estimated from their particle shape and size distribution, specific surface area, color, acid and base resistance.

\section{Experimental Procedure}

The $0.1 \mathrm{~mol} / \mathrm{L}$ of nickel nitrate, $\mathrm{Ni}\left(\mathrm{NO}_{3}\right)_{2}$, solution was mixed with $0.1 \mathrm{~mol} / \mathrm{L}$ of phosphoric acid solution in the molar ratio of $\mathrm{Ni} / \mathrm{P}=3 / 2$. This ratio is settled from the chemical composition of nickel orthophosphate, $\mathrm{Ni}_{3}\left(\mathrm{PO}_{4}\right)_{2}$. The certain part of nickel nitrate was substituted with ammonium cerium nitrate, $\left(\mathrm{NH}_{4}\right)_{2} \mathrm{Ce}\left(\mathrm{NO}_{3}\right)_{6}$, in the molar ratio of $\mathrm{Ni} / \mathrm{Ce}=10 / 0,9 / 1,8 / 2,5 / 5,2 / 8$, and $0 / 10[12,13]$. For the valence balance, two nickel cations were replaced with one cerium cation. Finally, the solutions were mixed in the molar ratio of $\mathrm{Ce} / \mathrm{P}=3 / 4$. This ratio is corres- 
ponding to $\mathrm{Ce}_{3}\left(\mathrm{PO}_{4}\right)_{4}$. Then, the mixed solution was adjusted to $\mathrm{pH} 7$ by ammonia solution. The precipitate was filtered off and dried in air condition. All chemicals were of guaranteed reagents from Wako Chemical Industries Ltd. (Osaka, Japan) without further purification.

A part of the precipitates was dissolved in hydrochloric acid solution. The ratios of phosphorus and cerium in the precipitates were also calculated from ICP results of these solutions, using SPS1500VR, Seiko Instruments Inc. The thermal behavior of these materials was analyzed by TG-DTA and XRD. TG and DTA curves were measured with a Shimadzu DTG-60H at a heating rate of $10^{\circ} \mathrm{C} / \mathrm{min}$ under air. XRD patterns were recorded on a Rigaku Denki RINT 1200 M X-Ray diffractometer using monochromated $\mathrm{CuK} \alpha$ radiation.

The powder properties of thermal products at $200^{\circ} \mathrm{C}$, $400^{\circ} \mathrm{C}, 600^{\circ} \mathrm{C}$, and $800^{\circ} \mathrm{C}$ were characterized by particle shape, particle size distribution, specific surface area, and their color. Particle shapes were observed by scanning electron micrographs (SEM) using JGM-5510LV, JEOL Ltd. Particle size distribution was measured with laser diffraction/scattering particle size distribution HORIBA LA-910. Specific surface areas of phosphates were calculated from the amount of nitrogen gas adsorbed at the temperature of liquid nitrogen by BET method with Belsorp mini from BEL JAPAN, INC. The color of phosphate pigments was estimated by ultraviolet-visible (UVVis) reflectance spectra with a Shimadzu UV2550.

Furthermore, the acid and base resistance of materials was estimated in following method. The $0.1 \mathrm{~g}$ of thermal products was allowed to stand in $100 \mathrm{ml}$ of $0.1 \mathrm{wt} \%$ sulphuric acid or $0.1 \mathrm{wt} \%$ sodium hydroxide solution for 1 day. Then, solid was removed off by filtration, the solution was dilute with nitric acid for ICP measurement. The concentrations of phosphorus, nickel, cerium cation were calculated by ICP results. As a resistance estimation, the solubility $(\%)$ of target elements was calculated to divide by the concentration that thermal products were completely dissolved by hot hydrochloric acid.

\section{Results and Discussion}

\subsection{Chemical Composition of Nickel-Cerium Phosphates}

Table 1 shows ICP results of samples synthesized in Ni/Ce ratios. From the valence of nickel, cerium cations, and phosphate anion, hydrogen ratio was calculated in the following equation.

$$
\begin{aligned}
& \mathrm{z}(\text { hydrogen rafio }) \\
& =3-2 \mathrm{x}(\text { nichel ratio })-4 \mathrm{y}(\text { cerium ratio })
\end{aligned}
$$

The negative value of $\mathrm{z}$ means the existence of hydroxide anion. Sample prepared in $\mathrm{Ni} / \mathrm{Ce}=10 / 0$ had the near ratio with nickel hydrogenphosphate, $\mathrm{NiHPO}_{4}$. On the other hand, cerium ratio was enough high at samples prepared in $\mathrm{Ni} / \mathrm{Ce}=0 / 10$. Cerium orthophosphate was considered to form with cerium hydroxide in this condition. In the middle $\mathrm{Ni} / \mathrm{Ce}$ ratios, cerium ratio was lower than that in preparation process. In previous works $[12,13]$, rare earth ratio in precipitates was higher than that in preparation conditions. This phenomenon was caused from that rare earth phosphates have smaller solubility than transition metal phosphates. In the case of tetravalent cerium phosphate, this tendency was not appeared. However, it is not clear why the ratio of cerium became lower than preparation condition.

Figure 1 shows DTA curves of nickel-cerium phosphates prepared in various $\mathrm{Ni} / \mathrm{Ce}$ ratios. DTA curves of sample prepared in $\mathrm{Ni} / \mathrm{Ce}=10 / 0$ had large endo- thermic peak at $100^{\circ} \mathrm{C}$, small endothermic peak at $250^{\circ} \mathrm{C}$, and small exothermic peak at $770^{\circ} \mathrm{C}$ (Figure 1(a)). These peaks were due to the volatilization of water, dehy- dration condensation of phosphate, and crystallization of nickel phosphate, respectively [12]. Nickel hydrogenphosphate was condensed to nickel pyrophosphate in following reaction at $250^{\circ} \mathrm{C}$.

$$
2 \mathrm{NiHPO}_{4} \rightarrow \mathrm{Ni}_{2} \mathrm{P}_{2} \mathrm{O}_{7}+\mathrm{H}_{2} \mathrm{O}
$$

The substitution with cerium produced the exothermic peaks at the range from $260^{\circ} \mathrm{C}$ to $330^{\circ} \mathrm{C}$ (Figures 1(b)(f)). These peaks were related with the reduction of cerium cation [15]. Figure 2 shows TG curves of samples prepared in various $\mathrm{Ni} / \mathrm{Ce}$ ratios. Samples prepared in $\mathrm{Ni} / \mathrm{Ce}=10 / 0$ had large weight loss over 50\%. Nickel hydrogenphosphate had large amount of adsorbed and crystalline water. By the substitution with cerium cation, this weight loss became small.

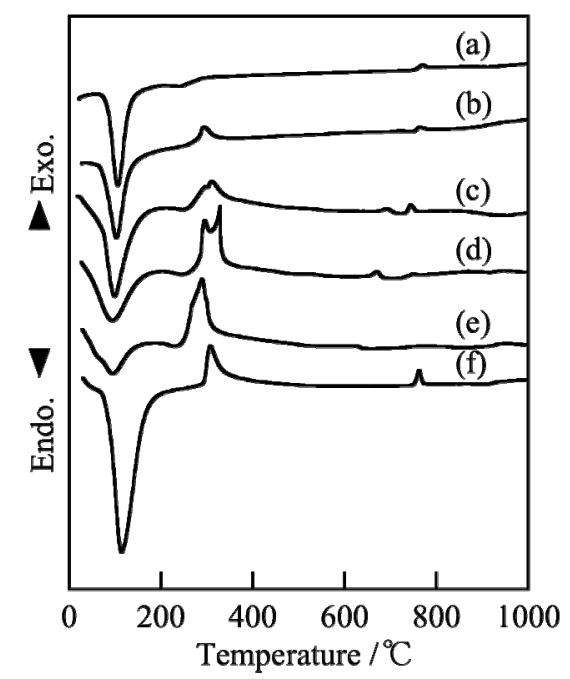

Figure 1. DTA curves of samples prepared in various $\mathrm{Ni} / \mathrm{Ce}$ ratios, (a) 10/0; (b) $9 / 1$; (c) $8 / 2$; (d) $5 / 5$; (e) $2 / 8$; and (f) $0 / 10$. 


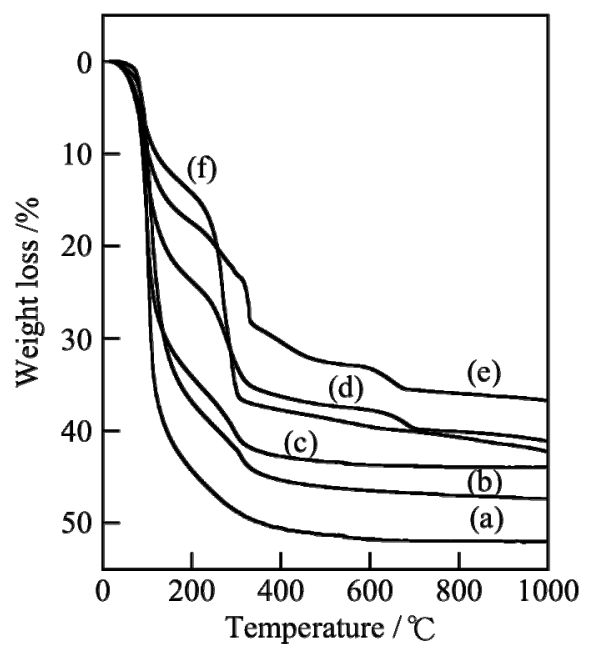

Figure 2. TG curves of samples prepared in various $\mathrm{Ni} / \mathrm{Ce}$ ratios, (a) $10 / 0$; (b) $9 / 1$; (c) $8 / 2$; (d) $5 / 5$; (e) $2 / 8$; and (f) $0 / 10$.

Samples prepared in $\mathrm{Ni} / \mathrm{Ce}=10 / 0-5 / 5$ indicated XRD peaks of $\mathrm{NH}_{4} \mathrm{H}_{2} \mathrm{PO}_{4}$. Samples heated at $200^{\circ} \mathrm{C}-600^{\circ} \mathrm{C}$ were amorphous phase in XRD analyses except for sample prepared in $\mathrm{Ni} / \mathrm{Ce}=0 / 10$ and then heated at $600^{\circ} \mathrm{C}$. This exceptional sample had the peaks of Monazite-type $\mathrm{CePO}_{4}$. Figure 3 shows XRD patterns of samples synthesized in various $\mathrm{Ni} / \mathrm{Ce}$ ratios and then heated at $800^{\circ} \mathrm{C}$. Sample prepared in $\mathrm{Ni} / \mathrm{Ce}=10 / 0$ had strong peaks of nickel pyrophosphate, $\mathrm{Ni}_{2} \mathrm{P}_{2} \mathrm{O}_{7}$. The peaks of Monazitetype $\mathrm{CePO}_{4}$ were observed in XRD patterns of ceriumsubstituted samples. Tetravalent cerium phosphate changed to trivalent cerium compound by heating.

We considered that the following reaction occurred in sample prepared at $\mathrm{Ni} / \mathrm{Ce}=0 / 10$.

$$
\mathrm{Ce}_{3}\left(\mathrm{PO}_{4}\right)_{4}+\mathrm{Ce}(\mathrm{OH})_{4} \rightarrow 4 \mathrm{CePO}_{4}+\mathrm{H}_{2} \mathrm{O}+\mathrm{O}_{2}
$$

The starting materials, the mixture of cerium phosphate and hydroxide, was suited to the $\mathrm{Ce} / \mathrm{P}$ ratio $(=0.986)$ in Table 1. Sample heated at $800^{\circ} \mathrm{C}$ indicated XRD peaks of $\mathrm{CePO}_{4}$ (Figure 3(f)). TG curves of ceriumsubstituted samples had weight loss at the range from $260^{\circ} \mathrm{C}$ to $330^{\circ} \mathrm{C}$ corresponding with exothermic peak in DTA curves (Figures 1, 2). These weight losses were caused from the volatilization of water and oxygen. The color of sample prepared in $\mathrm{Ni} / \mathrm{Ce}=0 / 10$ changed from yellow to white by heating at $400^{\circ} \mathrm{C}$. Tetravalent cerium phosphate was yellow powder and trivalent one was white powder.

\subsection{Powder Properties of Nickel-Cerium Phosphates}

Figure 4 shows SEM images of samples synthesized in various $\mathrm{Ni} / \mathrm{Ce}$ ratios. Sample prepared in $\mathrm{Ni} / \mathrm{Ce}=10 / 0$ consisted of small particles. On the other hand, samples prepared at high cerium ratios had large particles. The
Table 1. Chemical composition, NixCeyHzPO tates from ICP measurements.

\begin{tabular}{ccccc}
\hline $\mathrm{Ni} / \mathrm{Ce}^{*}$ & $\mathrm{x}$ & $\mathrm{y}$ & $\mathrm{z}$ & $\mathrm{Ni} / \mathrm{Ce}{ }^{* *}$ \\
\hline $10 / 0$ & 1.064 & 0 & 0.872 & $10 / 0$ \\
$9 / 1$ & 0.786 & 0.027 & 1.320 & $9 / 0.31$ \\
$8 / 2$ & 0.915 & 0.179 & 0.454 & $8 / 1.57$ \\
$5 / 5$ & 0.668 & 0.401 & 0.060 & $5 / 3.00$ \\
$2 / 8$ & 0.267 & 0.687 & -0.015 & $2 / 5.15$ \\
$0 / 10$ & 0 & 0.986 & -0.944 & $0 / 10$ \\
\hline
\end{tabular}

*: preparation condition; **: in precipitates.

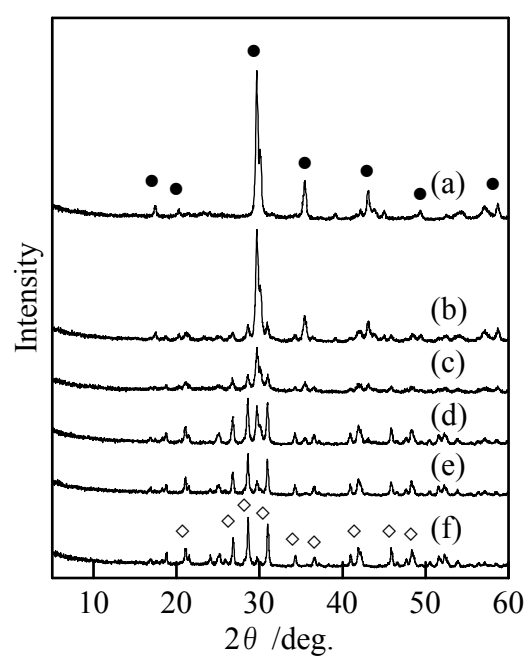

Figure 3. XRD patterns of samples prepared in various $\mathrm{Ni} / \mathrm{Ce}$ ratios and then heated at $800^{\circ} \mathrm{C}$, (a) $10 / 0$; (b) $9 / 1$; (c) $8 / 2$; (d) $5 / 5$; (e) $2 / 8$; and (f) $0 / 10, \bullet ; \mathrm{Ni}_{2} \mathrm{P}_{2} \mathrm{O}_{7}$ and $\diamond ; \mathrm{CePO}_{4}$.

specified shape like pillar was observed in samples prepared at $\mathrm{Ni} / \mathrm{Ce}=9 / 1$ and $5 / 5$. Samples prepared in $\mathrm{Ni} / \mathrm{Ce}$ $=2 / 8$ and $0 / 10$ had large particles.

Figure 5 shows the particle size distribution of samples synthesized in various $\mathrm{Ni} / \mathrm{Ce}$ ratios. The main part of particle of sample prepared in $\mathrm{Ni} / \mathrm{Ce}=10 / 0$ was from 100 to $10 \mu \mathrm{m}$ in size. Samples prepared in $\mathrm{Ni} / \mathrm{Ce}=9 / 1$ and $8 / 2$ had smaller particle size than sample prepared in $\mathrm{Ni} / \mathrm{Ce}=10 / 0$. In contrast, samples prepared in $\mathrm{Ni} / \mathrm{Ce}=$ $2 / 8$ and $0 / 10$ had much larger particles. Particle size distribution of samples prepared in this work was less affected by heating temperature.

Table 2 shows the specific surface area of samples synthesized in various $\mathrm{Ni} / \mathrm{Ce}$ ratios. Specific surface area as well as particle size has influence on color, and solubility of phosphate materials [16-19]. Sample prepared in $\mathrm{Ni} / \mathrm{Ce}=8 / 2$ had large specific surface area. On the other hand, sample prepared in $\mathrm{Ni} / \mathrm{Ce}=2 / 8$ had small specific surface area. The change of specific surface area 


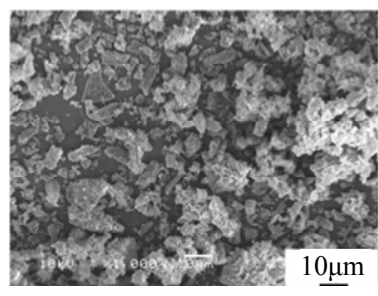

(a)

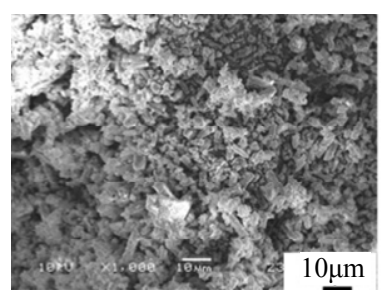

(c)

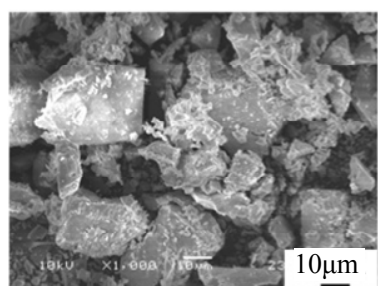

(e)

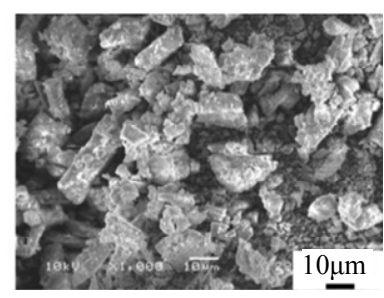

(b)

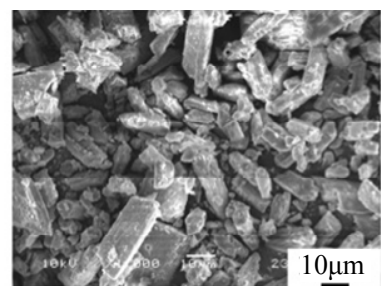

(d)

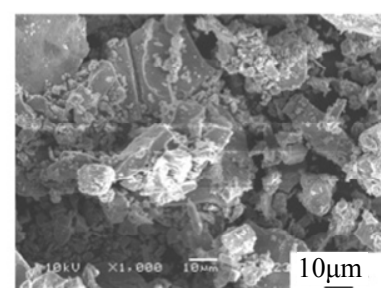

(f)
Figure 4. SEM images of samples prepared in various $\mathrm{Ni} / \mathrm{Ce}$ ratios, (a) $10 / 0$; (b) $9 / 1$; (c) $8 / 2$; (d) $5 / 5$; (e) $2 / 8$; and (f) $0 / 10$.

Table 2. Specific surface area of nickel-cerium phosphates $/ \mathrm{m}^{2} \cdot \mathrm{g}^{-1}$.

\begin{tabular}{ccccccc}
\hline Temp. & \multicolumn{6}{c}{$\mathrm{Ni} / \mathrm{Ce}$} \\
\hline${ }^{\circ} \mathrm{C}$ & $10 / 0$ & $9 / 1$ & $8 / 2$ & $5 / 5$ & $2 / 8$ & $0 / 10$ \\
200 & 42.83 & 43.63 & 62.43 & 22.43 & 1.13 & 29.99 \\
400 & 34.58 & 34.38 & 35.64 & 15.88 & 14.80 & 13.33 \\
600 & 26.54 & 24.64 & 28.40 & 11.33 & 21.34 & 38.12 \\
800 & 3.11 & 4.80 & 5.72 & 2.10 & 4.65 & 6.08 \\
\hline
\end{tabular}

was not proportional to the $\mathrm{Ni} / \mathrm{Ce}$ ratio. Samples prepared in all $\mathrm{Ni} / \mathrm{Ce}$ ratios had smaller specific surface area by heating at $800^{\circ} \mathrm{C}$.

\subsection{Pigmental Properties of Phosphates}

The color of samples without heating changed from light green to yellow with the increase of cerium ratio. By heating, light green of nickel hydrogenphosphate transformed to dark yellow powder of nickel pyrophosphate. The yellow powder of tetravalent cerium phosphate changed to the white powder of trivalent cerium phosphate by heating over $400^{\circ} \mathrm{C}$. Figure 6 shows UV-Vis reflectance

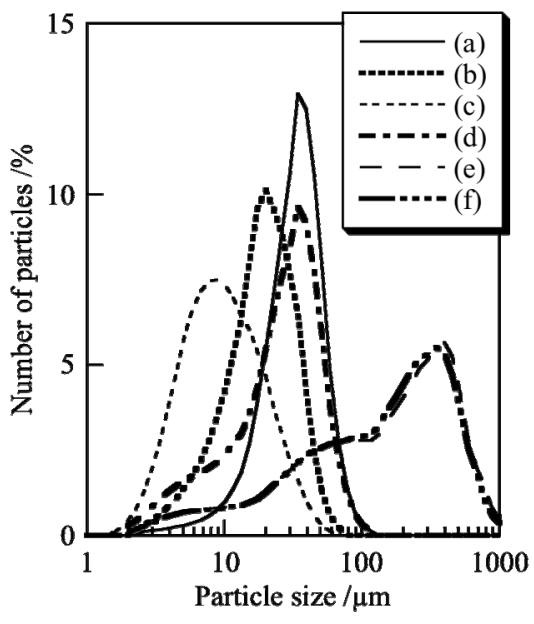

Figure 5. Particle size distribution of samples prepared in various Ni/Ce ratios, (a) 10/0; (b) $9 / 1$; (c) $8 / 2$; (d) $5 / 5$; (e) $2 / 8$; and (f) $0 / 10$.

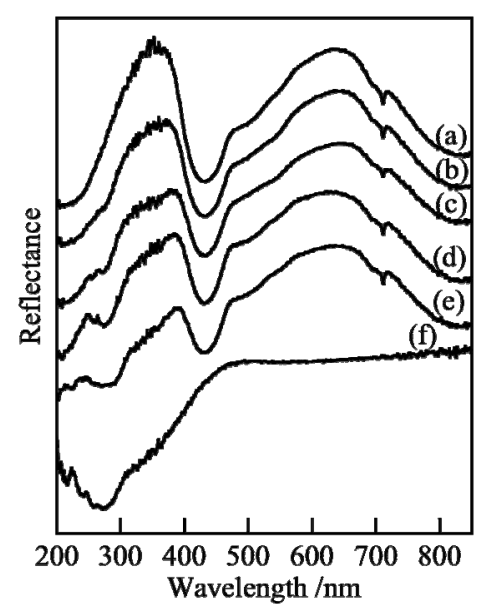

Figure 6. UV-Vis reflectance spectra of samples prepared in various $\mathrm{Ni} / \mathrm{Ce}$ ratios and then heated at $800^{\circ} \mathrm{C}$, (a) $10 / 0$; (b) $9 / 1$; (c) $8 / 2$; (d) $5 / 5$; (e) $2 / 8$; and (f) $0 / 10$.

spectra of samples synthesized in various $\mathrm{Ni} / \mathrm{Ce}$ ratios and then heated at $800^{\circ} \mathrm{C}$. Sample in $\mathrm{Ni} / \mathrm{Ce}=10 / 0$ had strong reflectance at 350 and $640 \mathrm{~nm}$ and weak reflectance at $430 \mathrm{~nm}$. By the substitution with cerium, the adsorption at $430 \mathrm{~nm}$ became smaller. The optical band gap energy of thermal products at 800 decreased from $5.17 \mathrm{eV}$ to $4.43 \mathrm{eV}$ [20]. The color of materials changed from yellow to white (Figure 7) [21].

Figure 8 shows acid resistance of samples synthesized in various $\mathrm{Ni} / \mathrm{Ce}$ ratios. The small number of solubility means high acid resistance. The eluted ratio of phosphorus changed from 100 to $28 \%$ with the increase of cerium ratio [22]. Formation of cerium phosphate inhibited the elution of phosphate materials. The elution ratio of nickel cation changed a little smaller by the substitution with cerium to $\mathrm{Ni} / \mathrm{Ce}=5 / 5$. Sample prepared in 


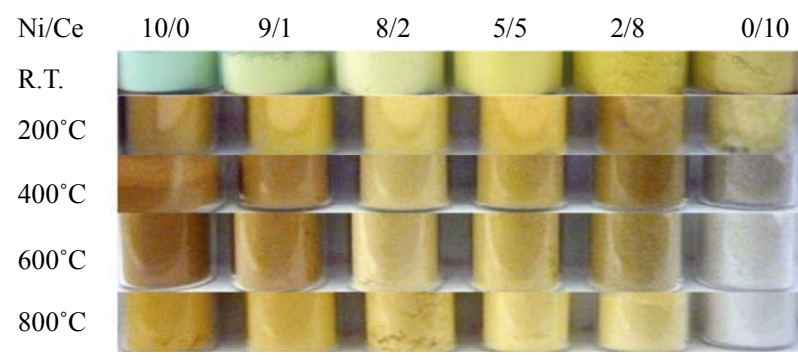

Figure 7. Photographs of samples prepared in various $\mathrm{Ni} / \mathrm{Ce}$ ratios.

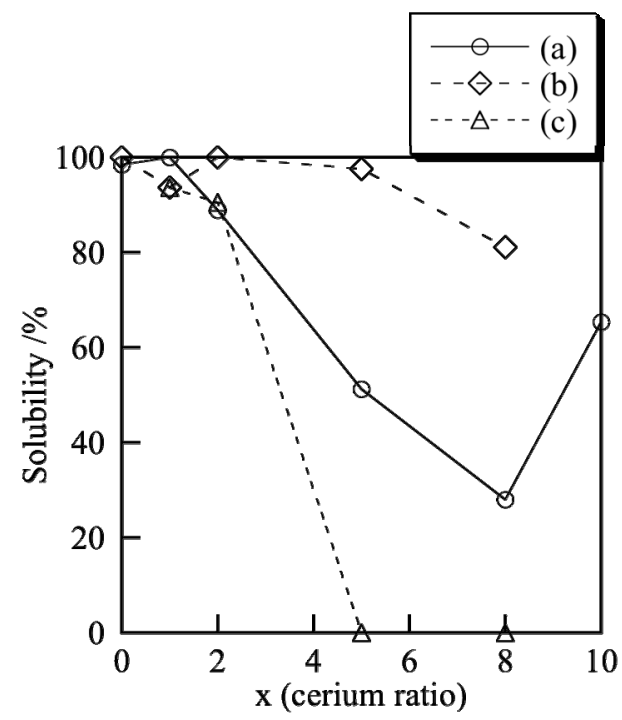

Figure 8. Acid resistance of samples prepared in various $\mathrm{Ni} / \mathrm{Ce}$ ratios, (a) phosphorus; (b) nickel; and (c) cerium.

Table 3. Elution ratio of phosphorus in basic solution/\%.

\begin{tabular}{ccccccc}
\hline Temp. & \multicolumn{5}{c}{$\mathrm{Ni} / \mathrm{Ce}$} \\
\hline${ }^{\circ} \mathrm{C}$ & $10 / 0$ & $9 / 1$ & $8 / 2$ & $5 / 5$ & $2 / 8$ & $0 / 10$ \\
R.T. & 87.47 & 93.67 & 90.54 & 75.00 & 48.43 & 40.23 \\
200 & 67.96 & 83.20 & 67.71 & 64.49 & 4.14 & 22.12 \\
400 & 62.70 & 52.26 & 47.50 & 5.13 & 2.05 & 16.16 \\
600 & 46.59 & 38.85 & 40.65 & 8.41 & 4.84 & 15.71 \\
800 & 0 & 1.01 & 0.05 & 0 & 8.28 & 0 \\
\hline
\end{tabular}

$\mathrm{Ni} / \mathrm{Ce}=5 / 5$ indicated small elution ratio of cerium cation.

In basic solution, all samples indicated no elution of nickel and cerium cations, because of the formation of their hydroxides. Table 3 shows the solubility of phosphorus in sodium hydroxide solution. The eluted ratio of phosphorus had the tendency to decrease with the increase of cerium ratio. Samples had high base resistance by hea- ting at high temperature.

\section{Conclusions}

In summary, nickel-cerium phosphates were prepared in aqueous solution. The obtained products were estimated for design of functional materials. The cerium ratio in precipitates was lower than that in preparation process. By the substitution of cerium cation, samples changed the mixture of nickel phosphate and cerium phosphate. The color of nickel phosphate was changed from light green to dark yellow by the substitution with cerium. The cerium substituted nickel phosphate changed to yellow powder by heating. The acid and base resistance of nickel phosphate materials improved by the substitution with cerium.

\section{REFERENCES}

[1] H. Onoda, H. Nariai, A. Moriwaki, H. Maki and I. Motooka, "Formation and Catalytic Characterization of Various Rare Earth Phosphates," Journal of Materials Chemistry, Vol. 12, No. 6, 2002, pp. 1754-1760. doi: $10.1039 / \mathrm{b} 110121 \mathrm{~h}$

[2] H. Onoda, T. Ohta, J. Tamaki and K. Kojima, "Decomposition of Trifluoromethane over Nickel Pyrophosphate Catalysts Containing Metal Cation," Applied Catalysis A: General, Vol. 288, No. 1-2, 2005, pp. 98-103. doi:10.1016/j.apcata.2005.04.028

[3] H. Onoda, K. Yokouchi, K. Kojima and H. Nariai, “Addition of Rare Earth Cation on Formation and Properties of Various Cobalt Phosphates," Materials Science and Engineering B, Vol. 116, No. 2, 2005, pp. 189-195. doi:10.1016/i.mseb.2004.10.002

[4] D. M. Lenz, M. Delamar and C. A. Ferreira, "Improvement of the Anticorrosion Properties of Polypyrrole by Zinc Phosphate Pigment Incorporation," Progress in Organic Coating, Vol. 58, No. 1, 2007, pp. 64-69.

[5] A. M. Mahdavian and M. M. Attar, "Investigation on Zinc Phosphate Effectiveness at Different Pigment Volume Concentrations via Electrochemical Impedance Spectroscopy," Eletrochimica Acta, Vol. 50, No. 24, 2005, pp. 4645-4648. doi:10.1016/i.electacta.2005.02.015

[6] M. A. Hernandez, F. Galliano and D. Landolt, "Mechanism of Cathodic Delamination Control of Zinc-Aluminum Phosphate Pigment in Waterborne Coatings," Corrosion Science, Vol. 46, No. 9, 2004, pp. 2281-2300. doi:10.1016/j.corsci.2004.01.009

[7] M. C. Deya, G. Blustein, R. Romagnoli and B. Amo, "The Influence of the Anion Type on the Anticorrosive Behaviour of Inorganic Phosphates," Surface and Coating Technology, Vol. 150, No. 2-3, 2002, pp. 133-142. doi:10.1016/S0257-8972(01)01522-5

[8] G. Li, Y. Shi, H. Hao, Z. Xia, Y. Lei, F. Guo and X. Li, "Effect of Rare Earth Addition on Shear Strength of $\mathrm{SnAgCu}$ Lead-Free Solder Joints," Journal of Materials Science: Materials in Electronics, Vol. 20, No. 2, 2009, pp. 186-192. doi:10.1007/s10854-008-9696-Z

[9] V. S. Vishnu, G. George and M. L. P. Reddy, "Effect of 
Molybdenum and Praseodymium Dopants on the Optical Properties of $\mathrm{Sm}_{2} \mathrm{Ce}_{2} \mathrm{O}_{7}$ : Tuning of Band Gaps to Realize Various Color Hues," Dyes and Pigments, Vol. 85, No. 3, 2010, pp. 117-123. doi:10.1016/j.dyepig.2009.10.012

[10] M. G. B. Nunes, L. S. Cavalcante, V. Santos, J. C. Sczancoski, M. R. M. Santos-Junior and E. Longo, "SolGel Synethsis and Characterization of $\mathrm{Fe}_{2} \mathrm{O}_{3} \cdot \mathrm{CeO}_{2}$ Doped with Pr Ceramic Pigments," Journal of Sol-Gel Science and Technology, Vol. 47, No. 1, 2008, pp. 38-43. doi:10.1007/s10971-008-1751-y

[11] V. S. Vishnu, G. George and M. L. P. Reddy, "Synthesis and Characterization of New Environmental Benign Tantalum-Doped $\mathrm{Ce}_{0.8} \mathrm{Zr}_{0.2} \mathrm{O}_{2}$ Yellow Pigments: Applications in Coloring of Particles," Dyes and Pigments, Vol. 82, No. 1,2009 , pp. 53-57. doi:10.1016/i.dyepig.2008.11.001

[12] H. Onoda, H. Matsui and I. Tanaka, "Improvement of Acid and Base Resistance of Nickel Phosphate Pigment by the Addition of Lanthanum Cation," Materials Science and Engineering B, Vo. 141, No. 1-2, 2007, pp. 28-33.

[13] H. Onoda H., K. Tange and I. Tanaka, "Influence of Lanthanum Addition on Preparation and Powder Properties of Cobalt Phosphates," Journal of Materials Science, Vol. 43, No. 16, 2008, pp. 5483-5488. doi:10.1007/s10853-008-2831-7

[14] D. Bregiroux, O. Terra, F. Audubert, N. Dacheux, V. Serin, R. Podor and D. Bernache-Assollant, "Solid-State Synthesis of Monazite-Type Compounds Containing Tetravalent Elements," Inorganic Chemistry, Vol. 46, No. 24, 2007, pp. 10372-10382. doi:10.1021/ic7012123

[15] A. A. Hanna, S. M. Mousa, G. M. Elkomy and M. A. Sherief, "Synthesis and Microstructure Studies of Nanosized Cerium Phosphates," European Journal of Chemistry, Vol. 1, No. 3, 2010, pp. 211-215. doi:10.5155/eurjchem.1.3.211-215.69

[16] F. Rohner, F. O. Ernst, M. Arnold, M. Hilde, R. Biebin- ger, F. Ehrensperger, S. E. Pratsinis, W. Langhans, R. F. Hurrell and M. B. Zimmermann, "Synthesis, Characterization, and Bioavailability in Rats of Ferric Phosphate Nanoparticles," The Journal of Nutrition, Vol. 137, No. 3, 2007, pp. 614-619.

[17] M. Badsar and M. Edrissi, "Synthesis and Characterization of Different Nanostructures of Cobalt Phosphate," Materials Research Bulletin, Vol. 45, No. 9, 2010, pp. 1080-1084. doi:10.1016/j.materresbull.2010.06.022

[18] N. H. M. Kamel, W. S. Hegazy and J. D. Navratil, "Solubility and Sorption Properties of Some Phosphate Fertilizer Components on Soils," Journal of Radio-analytical and Nuclear Chemistry, Vol. 284, No. 3, 2010, pp. 653-658. doi:10.1007/s10967-010-0535-3

[19] T. J. Brunner, M. Bohner, C. Dora, C. Gerber and W. J. Stark, "Comparison of Amorphous TCP Nanoparticles to Micron-Sized $\alpha$-TCP as Starting Materials for Calcium Phosphate Cements," Journal of Biomedical Materials Research, Vol. 83B, No. 2, 2007, pp. 400-407. doi:10.1002/jbm.b.30809

[20] J. C. Sczamcoski, L. S. Cavalcante, N. L. Marana, R. O. da. Silve, R. L. Tranquilin, M. R. Joya, P. S. Pizani, J. A. Sambrano, M. S. Li, E. Longo and J. Andres, "Electronic Structure and Optical Properties of $\mathrm{BaMoO}_{4}$ Powders," Current Applied Physics, Vol. 10, No. 2, 2010, pp. 614-624. doi:10.1016/j.cap.2009.08.006

[21] E. P. Lokshin, O. A. Tareeva and T. G. Kashulina, "Effect of Sulfuric Acid and Sodium Cation on the Solubility of Lanthanides in Phosphoric Acid," Russian Journal of Applied Chemistry, Vol. 81, No. 1, 2008, pp. 1-7. doi:10.1134/S1070427208010011

[22] E. P. Lokshin, O. A. Tareeva and T. G. Kashulina, "Effect of Sulfuric Acid and Sodium Cation on the Solubility of Lanthanides in Phosphoric Acid," Russian Journal of Applied Chemistry, Vol. 81, No. 1, 2008, pp. 1-7. doi:10.1134/S1070427208010011 